\title{
THE EHLERS-DANLOS SYNDROME AND METASTATIC MEDULLARY THYROID CARCINOMA: A CASE REPORT
}

\author{
Lina Zabuliene ${ }^{1,2}$, Airida Audrone Bagdziuniene ${ }^{3}$, Birute Burnyte ${ }^{4}$, \\ Ramunas Janavicius ${ }^{5}$, Jurgita Urboniene ${ }^{6}$, Algirdas Utkus ${ }^{4}$
}

${ }^{1}$ Clinics of Rheumatology, Traumatology-Orthopaedics and Reconstructive Surgery, Faculty of Medicine, Vilnius University, Vilnius,

Lithuania; ${ }^{2}$ Antakalnio out-patient clinic, Vilnius, Lithuania; ${ }^{3}$ Centre of Endocrinology, Vilnius University Hospital Santariskiu Klinikos, Vilnius, Lithuania; ${ }^{4}$ Department of Human and Medical Genetics, Faculty of Medicine, Vilnius University, Vilnius, Lithuania; ${ }^{5}$ Department of Molecular and Regenerative Medicine, Hematology, Oncology and Transfusion Medicine Center, Vilnius University Hospital Santariskiu klinikos, Vilnius, Lithuania; ${ }^{6}$ Infectious Diseases and Tuberculosis Hospital, Vilnius University hospital Santariskiu klinikos, Vilnius, Lithuania

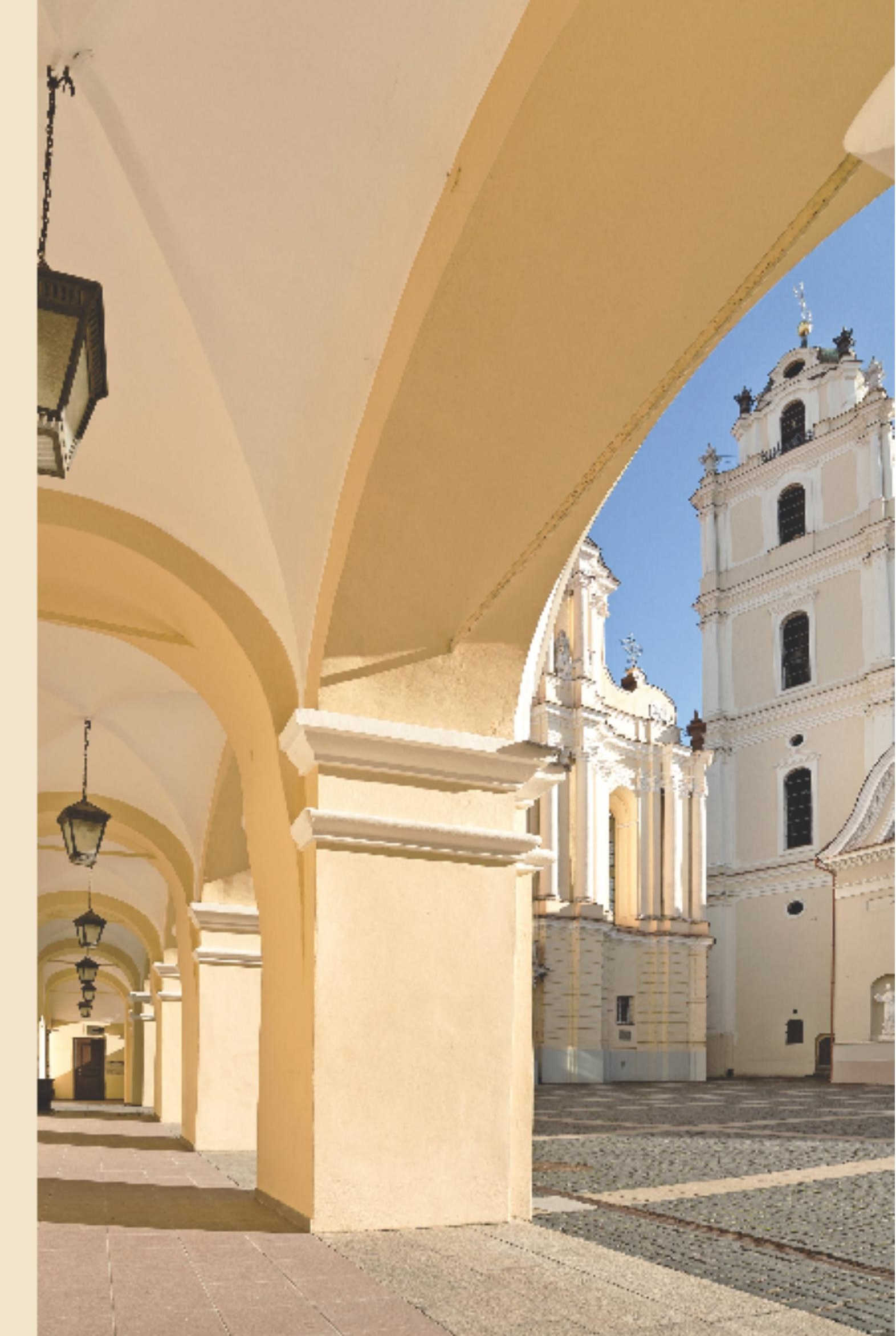

\section{INTRODUCTION:}

The Ehlers-Danlos syndrome (EDS) classic type is a heritary disorder of connective tissue, characterized by fragility and hyperextensibility of skin, abnormal wound healing, and joint hypermobility, due to COL5A1 or COL5A2 genes mutations. The diagnosis of EDS is mainly clinical. Milder variants of the classical type of the EDS are common in the population and can be identified by a well-defined clinical scoring system [1-4]. Multiple endocrine neoplasia, type 2A (MEN2A) is a syndrome defined by a medullary carcinoma, pheochromocytoma, hyperparathyroidism, and occasionally cutaneous lichen amyloidosis, because of mutations in RET proto-oncogene [5-8]. COL5A and RET genes mutations are linked to conditions affecting the human integumentary system and may coexist.

\section{CASE REPORT:}

An 18-year-old Caucasian female was consulted by an endocrinologist in February 2014.

The patient was born by a full term normal delivery with any neonatal or perinatal morbidity. She was the only child in the family. Her psychomotor development was normal. Since childhood she was very flexible, attended rhythmic gymnastics classes. At age of 12 suddenly she felt discomfort, pain in the left hip during movement, started tolimp. After few weeks the patient developed hip luxation and underwent internal fixation with screws. At age of 14 deformations of the pelvis and lumbar spine occurred, knee valgus position appeared. At 15 years patient was consulted at Toronto hospital, juvenile epiphysiolisis was diagnosed. She underwent left knee osteosynthesis followed by peroneal and tibial nerves damage, which caused impaired mobility at ankle and foot paresis.

In 2012 a small thyroid nodule was found and subclinical hypothyreosis was diagnosed; $25 \mathrm{mkg}$ of levothyroxin were prescribed.

In 2014 at age of 18 during self-examination, she noticed hard neck nodules. Ultrasonogra- phy showed a hypoechoic $0.4 \mathrm{~mm}$ diameter lesion in the right lobe of thyroid and both sides neck lymphadenopathy. FNAC of thyroid nodule revealed medullary carcinoma. On 11 Apr 2014 total thyroidectomy and necklymph node dissection was performed. Metastasis in 14 of 20 lymph nodes was found. 2.5 weeks after surgery calcitonin level was $1557.2 \mathrm{ng} / \mathrm{l}$ (normal range $0.5-7.8 \mathrm{ng} / \mathrm{l})$, she had normal serum calcium and parathyroid hormone levels and negative urinary catecholamines. She received 34 cycles of neck radiotherapy course and vandetanib therapy. She has been taking replacement dose of $125 \mathrm{mkg}$ levothyroxine per day. 23 Dec 2014 thyrotropin level was $0.195 \mathrm{mlU} / \mathrm{l}$ (normal range $0.27-3.75 \mathrm{mIU} / \mathrm{l}$ ), free thyroxin $20.98 \mathrm{pmol} / \mathrm{l}(12-22 \mathrm{pmol} / \mathrm{l}) ; 20$ Jan 2015 calcitonin - $1755.4 \mathrm{ng} / \mathrm{l}$.

Family history: the family history revealed no complaints on hyperextensibility of skin, abnormal wound healing or joint hypermobility in parents.

Her mother was diagnosed with primary parathyroid hyperplasia and MEN2A by mutational screening in all family members. She underwent total thyroidectomy and surgery for parathyroid adenoma. Father has multinodular goiter.

On physical examination: height $184 \mathrm{~cm}$, body mass index $16 \mathrm{~kg} / \mathrm{m}^{2}$, long face, long palms and fingers, joints' hypermobility, scoliosis, soft, velvety skin, hyperelasticity of face and elbow skin, widened atrophic scars, atrophic striae at the back, piezogenic papules.

Investigations:

- Abdominal ultrasound and CT: no pathological changes were found.

- Left shoulder CT: sclerotic proximal growth line of left humerus.

Body CT: multiple lymphnodes, lungs, pelvis bones and vertebrae metastases.

Bone scan: active head, humerus and pelvis focuses, most probable metastases.

Clinical geneticists' conclusion: Ehlers-Danlos syndrome; RET gene mutation at exon 13 (Y791F mutation), causing autosomal dominant MEN2A syndrome.

During our search for relevant literature on the web we did not find a similar case of co-occurrence of an aggressive form of MEN2A with Ehlers-Danlos syndrome. While there is a statistical chance that this rare combination of two syndromes may be incidental, genetic analysis may reveal the underlying genetic basis for the manifestations.

\section{CONCLUSIONS:}

If complicated growth and atypical phenotype is obvious, genetic counselling is desirable. Coexistent thyroid pathology might be inherited too. Careful patient's data collection and collaboration between health care specialists enables to achieve desirable outcomes.

\section{REFERENCES}

1. Lawrence EJ. The clinical presentation of Ehlers-Danlos syndrome Adv Neonatal Care 2005;5(6):301-14

2. Malfait F, Wenstrup R, De Paepe A. Ehlers-Danlos Syndrome, Classic Type. In: Pagon RA, Adam MP, Ardinger HH, Wallace SE, Amemiya A, Bean LJH, et al. editors. GeneReviews' [Internet]. Seattle (WA) University of Washington, Seattle; 1993-2015.

3. Malfait F, Wenstrup RJ, De Paepe A. Clinical and genetic aspects ofEhlers-Danlossyndrome,classictype.GenetMed2010;12(10):597605.

4. Malfait F, De Paepe A. The Ehlers-Danlos syndrome, a disorder with many faces. Adv Exp Med Biol 2014;802:129-43.

5. Walls GV. Multiple endocrine neoplasia (MEN) syndromes. Semin Pediatr Surg 2014;23(2):96-101.
6. Krampitz GW, Norton JA. RET gene mutations (genotype and phe notype) of multiple endocrine neoplasia type 2 and familial medullary thyroid carcinoma. Cancer 2014;120(13):1920-31.

7. Wells SA Jr, Pacini F, Robinson BG, Santoro M. Multiple endocrine neoplasia type 2 and familial medullary thyroid carcinoma: an update. J Clin Endocrinol Metab 2013;98(8):3149-64.

8. Valente FO, Dias da Silva MR, Camacho CP, Kunii IS, Bastos AU, da Fonseca CC, et all. Comprehensive analysis of RET gene should be performed in patients with multiple endocrineneoplasia type 2 (MEN 2) syndrome and no apparent genotype-phenotype correlation: an appraisal of p.Y791F and p.C634Y RET mutations in five unrelated Brazilian families. J Endocrinol Invest 2013;36(11):975-81. 